\title{
Ultrasound-assisted extraction of fructans from agave (Agave tequilana Weber var. azul) at different ultrasound powers and solid-liquid ratios
}

\author{
Miguel Ángel SÁNCHEZ-MADRIGAL ${ }^{1}$, Carlos Abel AMAYA-GUERRA ${ }^{1}$, Armando QUINTERO-RAMOS ${ }^{2 *}$, \\ Juan Gabriel BÁEZ-GONZÁLEZ¹, María Adriana NÚÑEZ-GONZÁLEZ¹, Martha Graciela RUIZ-GUTIÉRREZ", \\ José Antonio GARZÓN-TIZNADO
}

\begin{abstract}
The effects of ultrasound-assisted extraction (UAE) at different ultrasound power densities (UPDs; 40,80 , and $120 \mathrm{~mW} / \mathrm{mL}$ ) and solid:liquid (S:L) ratio (1:2, 1:3, and 1:6) on the extraction of carbohydrates from Agave tequilana plant of different ages were evaluated. Extracts obtained (6- and 7-year-old plant) were analyzed in the yield of carbohydrates (YC), fructan (FRU) content, simple sugars, fructan profile and the average degree of polymerization $\left(\mathrm{DP}_{\mathrm{n}}\right)$. UPD, S:L ratio, and plant age all affected YC, FRU, and DP. Maximum YC and FRU were obtained from the older agave with UPD and S:L ratio of $120 \mathrm{~mW} / \mathrm{mL}$ and 1:6, respectively; while glucose, fructose, and sucrose were highly released from the younger plant. Agave of 7-year-old presented the highest $\mathrm{DP}_{\mathrm{n}}$. Fructan degradation occurred at high UPD, increasing the simple sugars and decreasing the $\mathrm{DP}_{\mathrm{n}}$. Thermal-traditional extraction without sonication caused more fructan degradation; and overall, ultrasound enhanced fructan extraction and minimized fructan damage, representing a technological alternative for fructan extraction from agave.
\end{abstract}

Keywords: agave; fructans; ultrasound; power density; solid:liquid ratio; plant age.

Practical Application: Agave tequilana Weber var. azul plants have significant amounts of fructans. Extraction of these components by alternative methods such as ultrasound could represent advantages, improving the extraction and product quality. This research presents an alternative for the extraction of fructans assisted with ultrasound, evaluating different powers and solid-liquid ratios from agave heads of two different ages. Both variables, as well as age of agave showed a strong effect on fructan extraction. Ultrasound enhanced the extraction and minimized fructan damage, representing a technological alternative.

\section{Introduction}

Fructans are carbohydrates composed mainly of fructose units linked through fructosyl-fructose bonds in either linear or branched form. These are natural prebiotics that act as dietary fiber and are used in food technology, particularly for texture modification, moisture retention, gel formation, and food stabilization. Accordingly, fructans are considered a healthy food ingredient and their use in the food industry, primarily as fat and sugar substitutes, continues to grow (Apolinário et al., 2014; Zhu et al., 2016). Fructans are naturally present as storage carbohydrates in many species of plants and are associated with stress responses (cold and drought tolerance) of plants (Ritsema \& Smeekens, 2003). In Mexico, fructans are mainly obtained from agave plants; where the highest biodiversity of the Agave genus ( $75 \%$ of the 300 known species) is found (López \& Urías-Silvas, 2007). Agave tequilana Weber var. azul, commonly called blue agave (Waleckx et al., 2008), is the Agave species of the highest economic importance in Mexico, since it is the raw material for the production of tequila, which is the principal Mexican alcoholic beverage with denomination of origin, recognized, and consumed worldwide (López et al., 2003). However, according the Norma Oficial Mexicana (2006), the above-mentioned variety must be cultivated in the Jalisco state or in one of the other restricted regions of Mexico established as protected territories in order to obtain a product with denomination of origin of tequila. Because a lot of agave production takes place outside of these specified regions, and because tequila production has achieved an upper limit, the search for alternative products from these plants represents an important research focus. Due to the high level of fructans $(>60 \%)$ in agave (Mellado-Mojica \& López, 2012), the use of these plants as a source of fructans and different products such as agave syrup or fructan powders has been investigated. Agave fructans consist of a complex mixture of highly branched neo-fructans (agavins) with both $\beta$-(2-1) and $\beta$-(2-6) linkages between fructose moieties (López et al., 2003; Mancilla-Margalli \& López, 2006). This configuration renders the fructans resistant to enzymatic hydrolysis by human digestive enzymes, and they therefore pass undigested into the colon where they are fermented by colonic microflora. This prebiotic effect offers new alternative uses for agave fructans as functional ingredients in the food industry (López \& Urías-Silvas, 2007). 
Fructans are highly soluble in water and their solubility and mass transfer increase with temperature during the extraction process (Narváez-Flores et al., 2015). For this reason, the most common method for the extraction of fructans from chicory roots is hot water. Also, agave fructans, have been extracted with hot water at 75 and $80^{\circ} \mathrm{C}$ (López et al., 2003; Mancilla-Margalli \& López, 2006; Waleckx et al., 2008); however, this thermal process demands high-energy consumption and long extraction times (Zhu et al., 2016). Therefore, in the last years, the search for more sustainable and environment-friendly extraction methods, and following the principles of green chemistry, green extractions processes have become in an important research focus (Chemat et al., 2017). For this reason, alternative technologies such as UAE are being investigated and considered as a green extraction method ( $\mathrm{Li}$ et al., 2013). Some studies have been shown that UAE reduce the use of extraction solvents, processing time, and therefore, energy consumption enhancing during the extraction of the desired biocomponents (Chemat et al., 2011; Li et al., 2013; Chemat et al., 2017; Jacotet-Navarro et al., 2016). UAE is a technique in which acoustic energy and solvents are applied to extract target compounds from various plant matrices (Chemat et al., 2011). When solvents are sonicated, high-intensity sound waves are transmitted through the liquid medium, resulting in alternating cycles of compression and rarefaction, which in turn result in pressure changes, giving rise to a phenomenon called cavitation. This phenomenon result when small bubbles or voids are formed and - when they can no longer absorb energy - subsequently collapse violently, producing intense local heating, high pressures and shear forces, which result in micro-jetting streams directed towards the solid surface, generating several effects such as peeling, erosion and particle breakdown (Chemat et al., 2011; 2017). This process generates the energy required for create a chemical and mechanical effect, which promotes the release of soluble compounds from the raw plant tissue by disruption of the cell wall, enhancing mass transfer and facilitating both solvent penetration and the release of the desired biocomponents into the extraction medium (Ebringerová \& Hromádková, 2010; Chemat et al., 2017). Lingyun et al. (2007) extracted inulin from Jerusalem artichoke tubers with the aid of ultrasound: decreasing the extraction time. Milani et al. (2011) also reported on the use of UAE to improve inulin extraction from Burdock root, founding as optimum conditions $25 \mathrm{~min}, 83.2 \%$ of amplitude and $36.7^{\circ} \mathrm{C}$. A combination of treatments with ultrasound $\left(1135 \mathrm{~W} / \mathrm{m}^{2}\right.$ at 40 and $70^{\circ} \mathrm{C}$ ) was reported by Pardo-Rueda et al. (2015), leading to alterations in the plant cell structure in Dasylirion leiophyllum plants. Cell disruption by ultrasound (28-49 mW/mL) was also reported by Narváez-Flores et al. (2015) to enhance fructan extraction in A. tequilana. Although ultrasound has been applied to improve fructan extraction, this process depends on several factors including the ultrasound power used. According to Apolinário et al. (2014), caution must be exercised when using sonication to extract fructan type-inulin, since ultrasound may break the fructan molecules, forming low-molecular-weight fragments instead of the desired product (Lingyun et al., 2007), thereby diminishing their quality and functionality. Pardo-Rueda et al. (2015), for example, reported increased levels of simple sugars when sonication was combined with thermal treatments. Likewise, other factors such as temperature, extraction time
(Milani et al., 2011; Zhang et al., 2013; Pardo-Rueda et al., 2015; Narváez-Flores et al., 2015), and S:L ratio (Maran et al., 2013; Zhao et al., 2015; Flores-Girón et al., 2016; Zhang et al., 2016) have been identified as important factors that significantly affect polysaccharide extraction. These reports indicate the importance of carefully regulating the conditions under which ultrasound is applied in the extraction of fructans. Another factor influencing extraction yields in agave relates to the age of the plants, since the content and composition of agave fructans are functions of the age and physiological stage of the plants (Arrizon et al., 2010; Mellado-Mojica et al., 2009; Mellado-Mojica \& López 2012). Additionally, since the efficiency of the extraction is dependent on the S:L ratio, by correlation with technological aspects and mass transfer. This study raises explore the importance of this factor with physiological aspects of plant in an intensive extraction system as ultrasound, information which has not been reported. The aim of this study was to evaluate the effect of UPD and S:L ratio on the extraction of carbohydrates from Agave tequilana Weber var. azul plants of two different ages.

\section{Materials and methods}

\subsection{Chemicals and reagents}

D-Glucose (assay $\geq 99.0 \%$,), D-fructose (assay $\geq 99.5 \%$ ), and sucrose (assay $\geq 99.5 \%$ ) standards as well as inulin from chicory were purchased from Sigma-Aldrich (St. Louis, MO, USA). 1-Kestose, 1,1-kestotetraose, and 1,1,1-kestopentaose standards as well as fructan assay kit and fructanase mixture were obtained from Megazyme (Wicklow, Ireland). Other analytical grade reagents were purchased from Sigma-Aldrich and J.T. Baker (Mexico City, Mexico).

\subsection{Plant material}

Two Agave tequilana Weber var. azul heads of different ages (6 and 7 years of growth) were collected from the same cultivation zone of El Rosario, Sinaloa state, Mexico. The agave heads were stored at $4{ }^{\circ} \mathrm{C}$ and $90 \%$ relative humidity (RH) for three days before analysis. The plant materials were then analyzed physicochemically in terms of diameter, weight, and, soluble solids content ( $\left.{ }^{\circ} \mathrm{Brix}\right), \mathrm{pH}$ and proximate analysis, according to AOAC methods (Association of Official Analytical Chemists, 1996, 1998).

\subsection{Carbohydrate extraction from A. tequilana Weber var. azul}

The agave heads were cut transversally in two halves and then into four parts. Each of these pieces were then cut into smaller sections and ground in a domestic blender at the same velocity and time. The ground fresh agave material was immediately subjected to extraction with different S:L ratios $(w: v)$ of agave:water (1:2, 1:3, and 1:6) and UPDs (40, 80, and $120 \mathrm{~mW} / \mathrm{mL}$ ) for $35 \mathrm{~min}$ at $40^{\circ} \mathrm{C}$. Ultrasound was applied using a probe (Branson Ultrasonics Sonifier, S-450; 400 W, Danbury, CT) with a diameter of $13 \mathrm{~mm}$, which was kept immersed $3 \mathrm{~cm}$ below the surface of the liquid medium during sonication. The temperature was kept constant by recirculating water in a bath. Extraction in the absence of ultrasound, but under the same 
conditions, and extraction at $90^{\circ} \mathrm{C}$ with an intermediate $\mathrm{S}$ : $\mathrm{L}$ ratio and the same time were performed as controls. All extractions were performed in duplicate. At the end of each treatment, the resulting extract was filtered under vacuum through Whatman No. 1 paper. YC, FRU, fructose, glucose, and sucrose as well as the average degree of polymerization $\left(\mathrm{DP}_{\mathrm{n}}\right)$ were determined.

\subsection{Ultrasound power density calculation}

A calorimetric procedure described by Pardo-Rueda et al. (2015) was used to calculate the ultrasound power transferred into the liquid medium; and the temperature of the solvent during sonication (measured with a digital thermometer) was recorded as a function of time for each set of conditions. From the temperature increase due to cavitation plotted $v s$. time, the initial temperature increase $(d T / d t)$ was determined by polynomial curve fitting. The ultrasound power (UP) applied was then calculated by Equation 1:

$U P=m \times C_{p}\left(\frac{d T}{d t}\right)_{t=0}$

where $m$ is the solvent mass $(\mathrm{kg}), C_{p}$ is the specific heat of the solvent used $\left(4.18 \mathrm{~kJ} / \mathrm{kg} \cdot{ }^{\circ} \mathrm{C}\right)$, and $d T / d t$ is the change in temperature over time $\left({ }^{\circ} \mathrm{C} / \mathrm{s}\right)$. Finally, the ultrasound power that dissipated into the medium with volume $(\mathrm{V})$ was calculated as $\mathrm{D}=\mathrm{UP} / \mathrm{V}$ (Xu et al., 2014) and was expressed as ultrasound power density (UPD) in $\mathrm{mW} / \mathrm{mL}$.

\subsection{Analytical methods}

The moisture, protein, fat, fiber, and ash contents of the agave heads were measured according to AOAC (Association of Official Analytical Chemists, 1998) methods 950.02, 960.52, 920.39, 962.09, and 923.03, respectively; and carbohydrates were calculated by difference. Total soluble solids ( ${ }^{\circ}$ Brix) and $\mathrm{pH}$ were measured according to Association of Official Analytical Chemists (1996) methods 932.12, and 981.12, respectively. The total sugar content of the agave extracts was measured using the phenol-sulfuric acid method (Dubois et al., 1956) and the reducing sugar content was measured using the dinitrosalicylic (DNS) method (Miller, 1959). D-fructose was used as a standard in both cases. The percentage carbohydrate extraction yield (YC) was calculated using Equation 2:

$Y C(\%)=\frac{C_{t}-C_{r}}{\text { mass of agave }(g)} \times 100$

where $\mathrm{C}_{\mathrm{t}}$ and $\mathrm{C}_{\mathrm{r}}$ represent the total and reducing sugar contents (g), respectively. Fructan (FRU) content was determined using a fructan assay kit (Megazyme) as described by Narváez-Flores et al. (2015); and was expressed as g/100 g dry mass (d.m.) of agave.

\subsection{High performance anion exchange chromatography characterization of agave extracts}

The separation of fructans from agave extracts was performed by high-performance anion exchange coupled with pulsed amperometric detection (HPAEC-PAD) on a Thermo Scientific Dionex ICS-5000 ${ }^{+}$system (Sunnyvale, CA, USA) equipped with an electrochemical detector with a gold working electrode and an $\mathrm{AgCl}$ reference electrode. Before characterization, the extracts were passed through strong anionic and cationic resin exchangers, after which they were diluted to the appropriate concentration with deionized water. After filtration through a $0.45-\mu \mathrm{m}$ membrane, $25 \mu \mathrm{L}$ of sample was injected into the system using an autosampler. The sample was injected through an analytical CarboPac PA-100 column $(4 \times 250 \mathrm{~mm})$ with a guard column (Thermo Scientific; Dionex, Sunnyvalle, CA, USA). The column temperature was $30^{\circ} \mathrm{C}$ and a flow rate of $1 \mathrm{~mL} / \mathrm{min}$ was applied. The eluents used were (A) $150 \mathrm{mM}$ $\mathrm{NaOH}$ and (B) $1 \mathrm{M}$ sodium acetate diluted in $150 \mathrm{mM} \mathrm{NaOH}$. The elution gradient was $0-10 \mathrm{~min}$ with $100 \%$ eluent $\mathrm{A}, 10-85 \mathrm{~min}$ with a linear gradient from 0 to $45 \%$ eluent $\mathrm{B}$, and $85-90 \mathrm{~min}$ with $45 \%$ to $0 \%$ eluent B. Glucose, fructose, sucrose, 1-kestose (DP 3), 1,1-kestotetraose (DP 4), 1,1,1-kestopentaose (DP 5), and inulin from chicory were used as standards.

\subsection{Determination of the $D P_{n}$ of agave extracts}

$\mathrm{DP}_{\mathrm{n}}$ of the extracts were performed according to the method described by Ronkart et al. (2007). Fructanase mixture (Megazyme) was used to hydrolyze agave extracts. Glucose and fructose concentrations before and after hydrolysis were quantified by HPAEC-PAD.

\subsection{Experimental design and statistical analysis}

A statistical design of a $3 \times 3 \times 2$ completely randomized factorial experiment was employed to determine the influences of agave age, UPD, and S:L ratio on carbohydrate extraction. The data obtained from the various experimental analyses were subjected to analysis of variance (ANOVA) using Minitab version 16 software (Minitab, 2010). Differences between means across treatments were compared by Tukey's test with a confidence level of $95 \%$.

\section{Results and discussion}

\subsection{Physicochemical characterization of Agave tequilana plants of different ages}

Size dimensions (diameter and weight) as well as $\mathrm{pH},{ }^{\circ} \mathrm{Brix}$, and proximate composition of each agave head are shown in Table 1. Fold increases of 1.01 and 1.02 in diameter and weight, respectively, were observed in agave heads from 6 to 7 years. ${ }^{\circ}$ Brix and $\mathrm{pH}$ were also significantly higher in the older agave head $(P<0.05)$. The weights and diameters of both agave heads were lower than those reported by Arrizon et al. (2010) for an agave head of 6.5 years; however, a similar weight was reported by Iñiguez-Covarrubias et al. (2001) for an average of 30 agave heads of 7-9 years. In agreement with the present findings, Pinal et al. (2009) reported higher ${ }^{\circ}$ Brix levels in musts from 8 -year-old agaves than in those from 4-year-old agaves. Proximate composition analysis revealed that, after moisture content, carbohydrates made up the bulk of the plant matter, followed by crude fiber, ash, protein, and fat. A similar composition, but of dry matter, was previously reported by Narváez-Flores et al. (2015) and Flores-Girón et al. (2016). The content of most components differed significantly $(P<0.05)$ between the agave 
Table 1. Physicochemical properties of A. tequilana Weber var. azul plants of different ages.

\begin{tabular}{lrr}
\hline \multirow{2}{*}{ Properties } & \multicolumn{2}{c}{ Age (years) } \\
\cline { 2 - 3 } & \multicolumn{1}{c}{6} & \multicolumn{1}{c}{7} \\
\hline Diameter $(\mathrm{cm})$ & $116.0 \pm 0.50^{\mathrm{b}}$ & $118.1 \pm 0.40^{\mathrm{a}}$ \\
Weight $(\mathrm{kg})$ & $33.80 \pm 0.08^{\mathrm{b}}$ & $34.73 \pm 0.01^{\mathrm{a}}$ \\
${ }^{\circ}$ Brix & $2.00 \pm 0.08^{\mathrm{b}}$ & $2.25 \pm 0.05^{\mathrm{a}}$ \\
$\mathrm{pH}$ & $4.91 \pm 0.04^{\mathrm{b}}$ & $5.22 \pm 0.08^{\mathrm{a}}$ \\
Proximate composition (\%) & & \\
Moisture & $64.57 \pm 0.19^{\mathrm{a}}$ & $63.21 \pm 0.48^{\mathrm{b}}$ \\
Crude fiber & $2.51 \pm 0.06^{\mathrm{a}}$ & $2.49 \pm 0.01^{\mathrm{a}}$ \\
Ash & $0.96 \pm 0.03^{\mathrm{b}}$ & $1.16 \pm 0.05^{\mathrm{a}}$ \\
Protein & $0.46 \pm 0.01^{\mathrm{b}}$ & $0.75 \pm 0.02^{\mathrm{a}}$ \\
Fat & $0.15 \pm 0.05^{\mathrm{a}}$ & $0.16 \pm 0.03^{\mathrm{a}}$ \\
Carbohydrates & $31.36 \pm 0.22^{\mathrm{b}}$ & $32.20 \pm 0.02^{\mathrm{a}}$ \\
\hline
\end{tabular}

Mean \pm standard deviation. Means between ages with different superscript shows significant differences, Tukey's test $(P<0.05)$.

heads of different ages: only the crude fiber and fat contents did not differ $(P>0.05)$. All components except moisture were more highly represented in the 7-year-old agave head than in the younger plant. Differences between the two agaves were also identified in the extraction treatments: ANOVA (Table 2) revealed that age had a significant effect $(P<0.05)$ on YC, FRU, and $\mathrm{DP}_{\mathrm{n}}$. The results of the carbohydrate extraction of both agave heads are reported in Table 3, which shows that carbohydrate concentrations increased with age: YC and FRU content were higher in the 7-year-old than in the 6-year-old agave head. This difference can be attributed to physiological and morphological changes in agave plants over time (Mellado-Mojica et al., 2009). Similar results were reported by Arrizon et al. (2010), but in agave of 2, 4, and 6.5 years. Mellado-Mojica \& López (2012) also reported changes in FRU content during agave growth; and Mellado-Mojica et al. (2009) found the FRU content to increase with age in agave of 4,6 , and 8 years; and then to decrease again in agave of 10 years. Although the present study did not include plants older than 7 years, the plants evaluated in this study show carbohydrate contents adequate for the extraction of FRU from agave.

\subsection{Carbohydrate extraction from A. tequilana Weber var. azul}

Table 3 shows the YC and FRU contents as well as the $\mathrm{DP}_{\mathrm{n}}$ of the 6- and 7-year-old A. tequilana plants extracted with different UPDs and S:L ratios. The UPD was found to have a significant effect on carbohydrate extraction (Table 2). Sonication was shown to promote the extraction, since the YC and FRU contents at each S:L ratio were higher in sonicated samples than in samples extracted without ultrasound at the same temperature $\left(40^{\circ} \mathrm{C}\right)$. The extracts obtained without sonication differed significantly $(P<0.05)$ from those extracted with UPDs of 80 and $120 \mathrm{~mW} / \mathrm{mL}$. Under some treatment conditions, however, there were no significant differences between the sonicated samples and those extracted in the absence of sonication, especially in the case of higher S:L ratios (1:2 and 1:3). These findings demonstrate that the S:L ratio, like UPD, had a marked effect on carbohydrate extraction, as shown in the ANOVA results (Table 2), where different S:L ratios yielded significant differences $(P<0.05)$.
Table 2. Analysis of variance of the extraction yield of carbohydrates, the fructan contents and the degree of polymerization.

\begin{tabular}{lcccc}
\hline \multicolumn{1}{c}{ Source } & DF & YC & FRU & DP $_{\mathrm{n}}$ \\
\hline Age & 1 & 0.000 & 0.000 & 0.000 \\
$\mathrm{UPD}$ & 2 & 0.000 & 0.000 & 0.000 \\
S:L ratio & 2 & 0.000 & 0.000 & 0.000 \\
Age $^{\star} \mathrm{UPD}$ & 2 & 0.002 & 0.098 & 0.000 \\
Age $^{\star}$ S:L ratio & 2 & 0.289 & 0.036 & 0.110 \\
$\mathrm{UPD}^{\star} \mathrm{S}: \mathrm{L}$ ratio & 4 & 0.558 & 0.062 & 0.000 \\
Age $^{\star} \mathrm{UPD}{ }^{\star} \mathrm{S}: \mathrm{L}$ ratio & 4 & 0.006 & 0.893 & 0.096 \\
\hline Significant at $P<0.05$. UPD, ultrasound power density; S:L, solid:liquid; YC, extraction \\
yield of carbohydrates; FRU, fructans; $\mathrm{DP}_{\mathrm{n}}$, average degree of polymerization.
\end{tabular}

The highest levels of extracted $\mathrm{YC}$ and FRU were achieved at the maximum UPD tested $(120 \mathrm{~mW} / \mathrm{mL})$ in combination with a S:L ratio of 1:6. These extraction conditions yielded $\mathrm{YC}$ and FRU levels of $20.77 \%$ and $51.35 \mathrm{~g} / 100 \mathrm{~g}$ d.m., respectively, in 7-year-old agave; and $20.14 \%$ and $47.38 \mathrm{~g} / 100 \mathrm{~g} \mathrm{~d}$ d.m., respectively, in 6-year-old agave. These values differed significantly $(P<0.05)$ between samples extracted with 80 versus $120 \mathrm{~mW} / \mathrm{mL}$, as well as between samples extracted with S:L ratios of 1:3 versus 1:6. Only in the case of YC levels in the 7-year-old agave did the 80 and $120 \mathrm{~mW} / \mathrm{mL}$ UPDs not yield a significant difference. The higher YC and FRU levels observed in samples extracted in the presence of ultrasound, particularly at higher UPDs, can be attributed to an intensification of the cavitation phenomenon, which causes modifications and ruptures on the plant cell wall, thereby facilitating the transfer or release of carbohydrates into the extraction medium (Pardo-Rueda et al., 2015; Narváez-Flores et al., 2015; Chemat et al., 2017). At higher UPDs, more solvent (water) can enter the cells and more carbohydrates can thus permeate the cell membrane (Zou et al., 2010), which explains the enhanced carbohydrate yields with higher UPDs. Ultrasound has also been shown to induce chemical breakage of complex polysaccharides, which then contributes to higher carbohydrate quantification (Ebringerová \& Hromádková, 2010). Additionally, due the UAE was carried out at low temperature $\left(40^{\circ} \mathrm{C}\right)$ within acceptable limits of cavitation, this could influence and enhance the carbohydrate extraction yields. It has been reported that threshold limit of cavitation increases as the temperature decreases (Grönroos, 2010). Although this temperature is not the most suitable for carbohydrate solubilization, since the carbohydrate extraction yields increase with increasing temperature (Narváez-Flores et al., 2015); it has also been shown that higher temperatures reduce cavitation during ultrasound application, thereby counteracting their effect (Zhang et al., 2013; Pardo-Rueda et al., 2015) decreasing the extraction yield. This is due to at elevated temperatures an increase of vapor pressure is induced, causing more solvent vapors to enter the bubble cavity and numerous cavitation bubbles collapse less violently and reduce sonication effect (Santos et al., 2009; Chemat et al., 2017). As already mentioned, S:L ratio was shown in this study to affect YC and FRU yields from agave, where higher extraction yields were obtained with lower S:L ratios (1:6). This observation can be explained by the greater concentration difference between the tissue and the exterior solvent in lower S:L ratios, where the concentration difference results in enhanced extraction as a result of a greater driving force promoting the diffusion rate of soluble carbohydrates from the solid plant mass to the liquid extraction 
medium, thereby yielding an increased in extraction efficiency (Maran et al., 2013; Zhao et al., 2015). In addition, lower S:L ratios produce less viscous extraction media than higher S:L ratios, which also affects the efficiency of the cavitation phenomenon (Wang et al., 2014; Xu et al., 2014) and hence the extraction efficiency. For higher S:L ratios (higher amount of agave in the liquid medium), therefore, extraction yields in this study were lower due to the extraction of polysaccharides present in the raw material cannot be completed (Flores-Girón et al., 2016), by saturation of the liquid phase.

\subsection{Carbohydrate profiles and $D P_{n}$ from agave extracts obtained by HPAEC-PAD}

The agave extracts analyzed by HPAEC-PAD (Figure 1), revealed that fructose is the principal monomer present in fructans of A. tequilana, followed by disaccharide sucrose and monomer glucose. At S:L ratio of 1:6, the released glucose, fructose, and sucrose levels were higher than other S:L ratios. Accordingly, Figure 1 only shows the results for samples extracted at this 1:6 ratio at different UPDs. Figure 1 clearly demonstrates the pronounced effect of ultrasound on the release of simple sugars: the highest concentrations $(0.07486 \mathrm{~g} / 100 \mathrm{~g} \mathrm{~d}$.m. glucose (Figure 1a), $3.7281 \mathrm{~g} / 100 \mathrm{~g} \mathrm{~d} . \mathrm{m}$. fructose (Figure $1 \mathrm{~b}$ ), and $0.3009 \mathrm{~g} / 100 \mathrm{~g} \mathrm{~d} . \mathrm{m}$. sucrose (Figure 1c) were observed in extracts sonicated at $120 \mathrm{~mW} / \mathrm{mL}$. While higher simple sugar concentrations were obtained from extracts of 6-year-old agave, the 6- and 7-year-old agave extracts both exhibited the same trend of increasing carbohydrate concentrations with increasing UPD. Most extracts differed significantly $(P<0.05)$, particularly at higher UPDs $(80 \mathrm{~mW} / \mathrm{mL}$ and $120 \mathrm{~mW} / \mathrm{mL})$; except for the fructose content of 7-year-old agave, which did not differ significantly between UPDs (Figure 1b). It was also observed that the older agave contained significantly less glucose, fructose, and sucrose than the younger agave $(P<0.05)$. These findings are in agreement with the $\mathrm{DP}_{\mathrm{n}}$ s determined for the two plants

Table 3. Extraction yield of carbohydrates, fructan content, and degree of polymerization from A. tequilana Weber var. azul plants of different ages extracted at different ultrasound powers and solid:liquid ratios.

\begin{tabular}{|c|c|c|c|c|c|c|}
\hline \multicolumn{7}{|c|}{6 years } \\
\hline \multirow{2}{*}{ Determinations } & \multirow{2}{*}{ S:L ratio } & \multicolumn{4}{|c|}{$\mathrm{UPD}(\mathrm{mW} / \mathrm{mL})$} & \multirow{2}{*}{$\begin{array}{c}\text { Control } \\
90^{\circ} \mathrm{C}\end{array}$} \\
\hline & & 0 & 40 & 80 & 120 & \\
\hline \multirow{3}{*}{$\begin{array}{l}\text { YC } \\
(\%)\end{array}$} & $1: 2$ & $12.22 \pm 0.51^{g}$ & $13.28 \pm 1.17^{\mathrm{g}}$ & $14.50 \pm 1.30^{\text {efg }}$ & $15.97 \pm 1.14^{\mathrm{def}}$ & \multirow{3}{*}{$20.08 \pm 1.99^{\mathrm{ab}}$} \\
\hline & $1: 3$ & $12.55 \pm 0.62^{g}$ & $13.64 \pm 1.35^{\mathrm{fg}}$ & $16.87 \pm 1.66^{\text {cde }}$ & $18.82 \pm 0.69^{\mathrm{abc}}$ & \\
\hline & $1: 6$ & $12.73 \pm 0.62^{\mathrm{g}}$ & $14.43 \pm 1.56^{\mathrm{efg}}$ & $17.59 \pm 1.32^{\mathrm{bcd}}$ & $20.14 \pm 1.47^{\mathrm{a}}$ & \\
\hline \multirow{3}{*}{$\begin{array}{c}\text { FRU } \\
\text { (g/100 g d.m.) }\end{array}$} & $1: 2$ & $30.79 \pm 0.07^{\mathrm{f}}$ & $32.71 \pm 0.57^{\mathrm{ef}}$ & $35.70 \pm 0.93^{\mathrm{de}}$ & $38.50 \pm 1.63^{\mathrm{cd}}$ & \multirow{3}{*}{$53.28 \pm 0.57^{a}$} \\
\hline & $1: 3$ & $32.78 \pm 0.07^{\mathrm{ef}}$ & $35.09 \pm 1.28^{\mathrm{e}}$ & $38.50 \pm 1.20^{\mathrm{cd}}$ & $41.75 \pm 0.45^{c}$ & \\
\hline & $1: 6$ & $38.53 \pm 0.40^{\mathrm{cd}}$ & $40.40 \pm 0.96^{c}$ & $41.69 \pm 0.40^{c}$ & $47.38 \pm 0.78^{\mathrm{b}}$ & \\
\hline \multirow{3}{*}{$\mathrm{DP}_{\mathrm{n}}$} & $1: 2$ & $15.16 \pm 0.42^{\mathrm{ab}}$ & $14.85 \pm 0.02^{\mathrm{b}}$ & $14.76 \pm 0.05^{\mathrm{b}}$ & $14.61 \pm 0.20^{\mathrm{b}}$ & \multirow{3}{*}{$11.79 \pm 0.13^{\mathrm{d}}$} \\
\hline & $1: 3$ & $14.93 \pm 0.30^{\mathrm{b}}$ & $15.08 \pm 0.55^{\mathrm{ab}}$ & $15.72 \pm 0.03^{\mathrm{a}}$ & $14.68 \pm 0.30^{\mathrm{b}}$ & \\
\hline & $1: 6$ & $14.94 \pm 0.49^{\mathrm{b}}$ & $15.13 \pm 0.37^{\mathrm{ab}}$ & $14.92 \pm 0.18^{\mathrm{b}}$ & $13.69 \pm 0.31^{\mathrm{c}}$ & \\
\hline \multicolumn{7}{|c|}{7 years } \\
\hline \multirow{3}{*}{$\begin{array}{l}\mathrm{YC} \\
(\%)\end{array}$} & $1: 2$ & $12.99 \pm 0.52^{\mathrm{f}}$ & $14.84 \pm 0.25^{\mathrm{e}}$ & $16.86 \pm 0.31^{\mathrm{d}}$ & $18.11 \pm 0.46^{\mathrm{cd}}$ & \multirow{3}{*}{$20.16 \pm 1.03^{\mathrm{ab}}$} \\
\hline & $1: 3$ & $13.28 \pm 0.82^{\mathrm{f}}$ & $16.76 \pm 1.03^{\mathrm{d}}$ & $17.70 \pm 1.03^{\mathrm{cd}}$ & $19.60 \pm 0.64^{\mathrm{ab}}$ & \\
\hline & $1: 6$ & $15.27 \pm 0.29^{\mathrm{e}}$ & $18.90 \pm 0.25^{\mathrm{bc}}$ & $19.64 \pm 1.23^{\mathrm{ab}}$ & $20.77 \pm 0.67^{\mathrm{a}}$ & \\
\hline \multirow{3}{*}{$\begin{array}{c}\text { FRU } \\
\text { (g/100 g d.m.) }\end{array}$} & $1: 2$ & $33.03 \pm 0.45^{\mathrm{i}}$ & $34.23 \pm 0.48^{\mathrm{hi}}$ & $37.94 \pm 0.87^{\mathrm{efg}}$ & $40.63 \pm 0.84^{\mathrm{def}}$ & \multirow{3}{*}{$58.62 \pm 0.63^{\mathrm{a}}$} \\
\hline & $1: 3$ & $36.51 \pm 1.21^{\mathrm{ghi}}$ & $37.60 \pm 0.61^{\mathrm{fgh}}$ & $43.67 \pm 1.62^{\mathrm{cd}}$ & $45.79 \pm 0.47^{c}$ & \\
\hline & $1: 6$ & $41.50 \pm 0.01^{\mathrm{e}}$ & $43.32 \pm 0.24^{\mathrm{cd}}$ & $46.77 \pm 0.56^{c}$ & $51.35 \pm 1.84^{\mathrm{b}}$ & \\
\hline \multirow{3}{*}{$\mathrm{DP}_{\mathrm{n}}$} & $1: 2$ & $16.60 \pm 0.25^{\mathrm{bcd}}$ & $16.88 \pm 0.14^{\mathrm{bc}}$ & $16.08 \pm 0.03^{\mathrm{d}}$ & $14.67 \pm 0.07^{\mathrm{e}}$ & \multirow{3}{*}{$11.89 \pm 0.01^{g}$} \\
\hline & $1: 3$ & $16.38 \pm 0.04^{\text {cd }}$ & $18.05 \pm 0.03^{\mathrm{a}}$ & $17.12 \pm 0.04^{\mathrm{b}}$ & $14.77 \pm 0.71^{\mathrm{e}}$ & \\
\hline & $1: 6$ & $16.41 \pm 0.01^{\mathrm{cd}}$ & $17.82 \pm 0.04^{\mathrm{a}}$ & $15.98 \pm 0.01^{\mathrm{d}}$ & $13.70 \pm 0.47^{\mathrm{f}}$ & \\
\hline
\end{tabular}

Mean \pm standard deviation. Means by rows for UPD and by columns for S:L ratio with different superscript between ages shows significant differences, Tukey's test $(P<0.05)$. UPD, ultrasound power density; S:L, solid:liquid; YC, extraction yield of carbohydrates; FRU, fructans; $\mathrm{DP}_{\mathrm{n}}$, average degree of polymerization.

a)

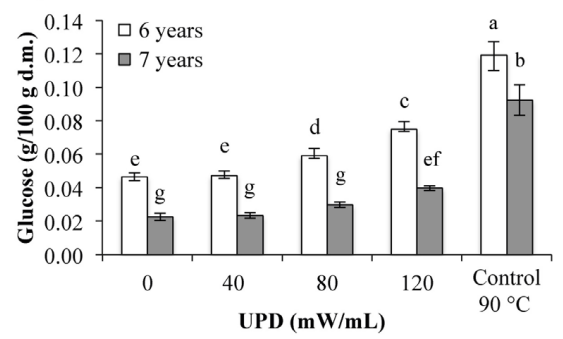

b)

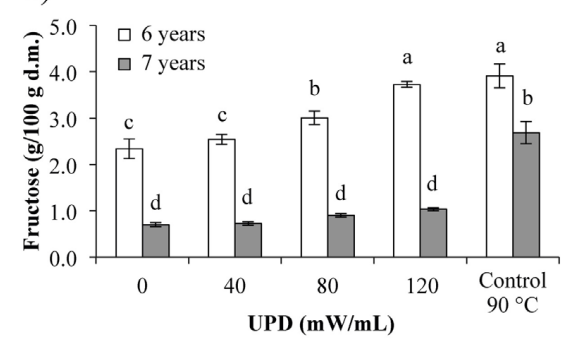

c)

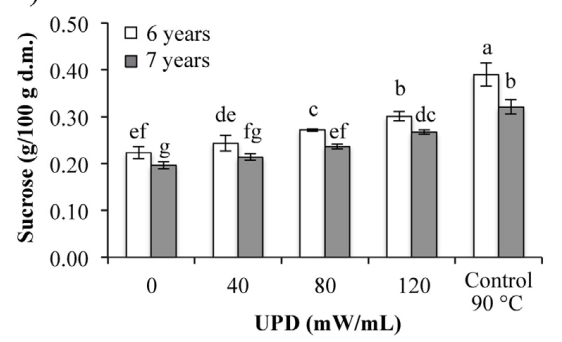

Figure 1. Glucose (a); fructose (b); and sucrose (c) contents in extracts of A. tequilana plants of 6 and 7 years extracted at different UPDs. Bars represent standard deviation; and mean values with different letters for the different extracts indicate significant differences according to the Tukey's test $(P<0.05)$. 
(Table 3): 13.70-18.05 for the 7-year-old plant and 13.69-15.72 for the 6-year-old plant, indicating that longer polymerized fructans are present in the older plant. These $\mathrm{DP}_{n} \mathrm{~s}$ are similar to those reported by Waleckx et al. (2008), who found the $\mathrm{DP}_{\mathrm{n}}$ of fructans from $A$. tequilana to be 13.6. The effects of ultrasound were also evident in DP $\mathrm{n}$ : extracts obtained by sonication at higher UPDs $(120 \mathrm{~mW} / \mathrm{mL})$ had lower $\mathrm{DP}_{\mathrm{n}} \mathrm{s}$, which indicates that high UPD can degrade fructans via glycosidic bond cleavage in both structural and branched polysaccharides (Ebringerová \& Hromádková, 2010; Pardo-Rueda et al., 2015), thereby shortening the chain length. This effect also was reported by Lingyun et al. (2007). This chain-shortening effect in fructans can be considered disadvantage or not, depending on their use when added to food as functional ingredient: since fructan properties including prebiotic activity, digestibility, health promoting potential, caloric value, sweetening power and water binding capacity, are dependent on DP ${ }_{n}$ (Apolinário et al., 2014; Zhu et al., 2016). Also, alterations in natural components have been reported during ultrasound application, such as lycopene, ascorbic acid, total phenolic and anthocyanin content, $\beta$-carotene, among others. Most degradation of these components is attributed to generation of $\mathrm{H}^{\cdot}$ and $\mathrm{OH}^{\cdot}$ radicals formed during sonication (Pingret et al., 2013). Compared with the extracts prepared at $90^{\circ} \mathrm{C}$ without ultrasound, the ultrasound-assisted extracts had lower FRU levels (Table 3), but higher $\mathrm{DP}_{\mathrm{n}} \mathrm{s}$, indicating more fructan degradation in the unsonicated heat-treated samples. In terms of fructan degradation, therefore, the UAE procedure represents an improved method for the extraction of fructans from agave plants compared with the traditional method (no sonication). With these results and considering that extraction conditions were realized at lower temperatures in the UAE method, this could be representing an advantage for possible applications at industrial level in relation of energy consumption.
For other hand the difference in fructan degradation levels between the traditional and the UAE method was also evident in the separation of fructans demonstrated by HPAEC-PAD (Figure 2): the fructan profile for the extract prepared at $90{ }^{\circ} \mathrm{C}$ (Figure 2c) exhibited less definition with higher peaks of glucose, fructose, and sucrose compared with the profile for the UAE products (Figure 2a and $2 \mathrm{~b}$ ), indicative of more fructan degradation in the heat-treated samples. Slightly higher levels of longer polymerized fructans were also observed in the 7-year-old plant than in the 6-year-old plant (Figure 2a and 2b, respectively). The HPAEC-PAD chromatograms of agave fructans revealed the presence of the fructooligosaccharides DP3, DP4, and DP5. 1-Kestose (10.59 min), 1,1-kestotetraose (22.75 min), and 1,1,1-kestopentaose $(27.80 \mathrm{~min}$ ) were identified in all extracts; and clear differences between ages were not observed for these compounds. In extracts prepared with heat treatment $\left(90^{\circ} \mathrm{C}\right)$, however, the peaks corresponding to these compounds were higher. The profiles showed in Figure 2 are in agreement with the $\mathrm{DP}_{\mathrm{n}}$ s presented in Table 3 as well as with the results shown in Figure 1, where free sugar contents (glucose, fructose, and sucrose) were shown to decrease from 6 to 7 years. This trend is similar to that reported by Arrizon et al. (2010) and Mellado-Mojica \& López (2012), who demonstrated linear decreases in free sugar content with increasing agave plant ages (from 2 to 6.5 years and from 2 to 7 years, respectively).

The identification of molecules with long DPs in A. tequilana is difficult; because their fructans exist as a complex mixture of highly branched neo-fructans with $\beta-(2-1)$ and $\beta-(2-6)$ linkages between fructose moieties (López et al., 2003; Mancilla-Margalli \& López, 2006), which is more complex than the simple inulin series (linear $\beta$-(2-1)-linked series) from chicory.
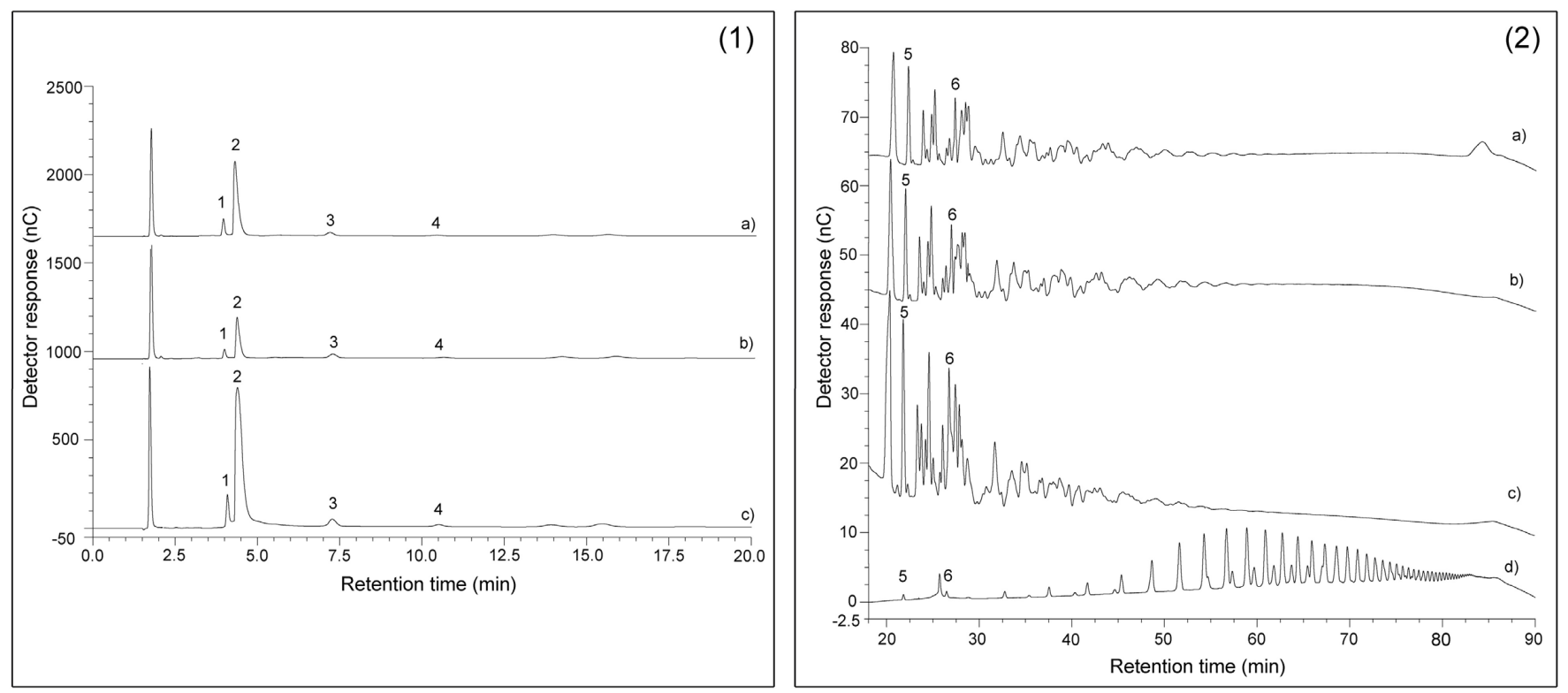

Figure 2. HPAEC-PAD profile of fructans obtained from A. tequilana plants of different ages extracted at $120 \mathrm{~mW} / \mathrm{mL}$ and a solid:liquid ratio of 1:3. (a) 6 years; (b) 7 years; (c) control without ultrasound at $90^{\circ} \mathrm{C}$; and (d) inulin from chicory. Peaks 1, 2, 3, 4, 5, and 6 were identified by comparison with standards of known retention time and correspond to glucose, fructose, sucrose, 1-kestose, 1,1-kestotetraose, and 1,1,1-kestopentaose, respectively. 
The separation of fructans from agave extracts in this study (Figure 2) was thus not as clear as that observed for inulin from chicory (Figure 2d). For this reason, the complex structure determined for the agave extracts (Figure 2) did not allow for accurate quantification of $\mathrm{DP}_{\mathrm{n}}$. López et al. (2003), Mellado-Mojica et al. (2009), Arrizon et al. (2010), and Mellado-Mojica \& López (2012), however, also identified a complex fructan structure in A. tequilana using HPAEC-PAD and reported DPs of 3 to 29,3 to 28,8 to 30 , and 6 to 23 , respectively.

\section{Conclusions}

The extraction of carbohydrates from A. tequilana Weber var. azul was enhanced by the use of ultrasound. Both UPD and S:L ratio significantly affected carbohydrate extraction: the highest UPD and the lowest S:L ratio yielded the highest levels of YC, glucose, fructose, sucrose, and FRU. The 7-year-old agave plant yielded the highest YC and FRU levels but the lowest glucose, fructose, and sucrose levels. The $\mathrm{DP}_{\mathrm{n}}$ was higher in the older plant (7 years), indicating the presence of longer fructan polymers. The higher UPD was also shown to result in some fructan degradation, diminishing the $\mathrm{DP}_{\mathrm{n}} \mathrm{s}$ in both agaves heads. Despite of this effect, the extraction of high levels of carbohydrates using ultrasound may be advantageous over the traditional thermal extraction methods, which produce higher degradation of fructans with lower $\mathrm{DP}_{\mathrm{n}}$ s. Additionally, considering the extraction temperature in both methods, the UAE could represents lower energy consumption compared with thermal-traditional treatment at high temperatures. These results suggest that UAE technology is promising for extraction of fructans and other polysaccharides found in different plants. However, for consider this technology as a superior method, for application at industrial scale, further studies are required for evaluation of this process such as the energy consumption that can be assessed in conjunction with the best conditions for the extraction of fructans from these plant types (Agavaceas).

\section{Acknowledgements}

The authors acknowledge the National Council of Science and Technology (CONACYT-Mexico) for financial support via a Basic Research Project Grant (no: 182169) and Convocatoria de Ciencia Básica SEP-CONACYT 2012.

\section{References}

Apolinário, A. C., Lima Damasceno, B. P. G., Macêdo Beltrão, N. E., Pessoa, A., Converti, A., \& Silva, J. A. (2014). Inulin-type fructans: a review on different aspects of biochemical and pharmaceutical technology. Carbohydrate Polymers, 101, 368-378. http://dx.doi. org/10.1016/j.carbpol.2013.09.081.

Arrizon, J., Morel, S., Gschaedler, A., \& Monsan, P. (2010). Comparison of the water- soluble carbohydrate composition and fructan structures of Agave tequilana plants of different ages. Food Chemistry, 122(1), 123-130. http://dx.doi.org/10.1016/j.foodchem.2010.02.028.

Association of Official Analytical Chemists - AOAC. (1996). Official Methods of Analysis of Association of Official Analytical Chemists (16th ed.). Washington: AOAC International.
Association of Official Analytical Chemists - AOAC. (1998). Official Methods of Analysis of Association of Official Analytical Chemists (15th ed.). Washington: AOAC International.

Chemat, F., Huma, Z., \& Khan, M. (2011). Application of ultrasound in food technology: processing, preservation and extraction. Ultrasonics Sonochemistry, 18(4), 813-835. http://dx.doi.org/10.1016/j. ultsonch.2010.11.023.

Chemat, F., Rombaut, N., Sicaire, A. G., Meullemiestre, A., Fabiano-Tixier, A. N., \& Abert-Vian, M. (2017). Ultrasound assisted extraction of food and natural products. Mechanisms, techniques, combinations, protocols and applications: a review. Ultrasonics Sonochemistry, 34, 540-560. http://dx.doi.org/10.1016/j.ultsonch.2016.06.035.

Dubois, M., Gilles, K. A., Hamilton, J. K., Rebers, P. A., \& Smith, F. (1956). Colorimetric method for determination of sugar and related substances. Analytical Chemistry, 28(3), 350-356. http://dx.doi. org/10.1021/ac60111a017.

Ebringerová, A., \& Hromádková, Z. (2010). An overview on the application of ultrasound in extraction, separation and purification of plant polysaccharides. Central European Journal of Chemistry, 8(2), 243-257. http://dx.doi.org/10.2478/s11532-010-0006-2.

Flores-Girón, E., Salazar-Montoya, J. A., \& Ramos-Ramírez, E. G. (2016). Application of a Box-Behnken design for optimizing the extraction process of agave fructans (Agave tequilana Weber var. Azul). Journal of the Science of Food and Agriculture, 96(11), 38603866. http://dx.doi.org/10.1002/jsfa.7582.

Grönroos, A. (2010). Ultrasonically enhanced disintegration: polymers sludge, and contaminated soil. 1st ed. Finland: VTT Publications.

Iñiguez-Covarrubias, G., Díaz-Teres, R., Sanjuan-Dueñas, R., AnzaldoHernández, J., \& Rowell, R. M. (2001). Utilization of by-products from the tequila industry. Part 2: Potential value of Agave tequilana Weber azul leaves. Bioresource Technology, 77(2), 101-108. http:// dx.doi.org/10.1016/S0960-8524(00)00167-X.

Jacotet-Navarro, M., Rombaut, N., Deslis, S., Fabiano-Tixier, A. N., Pierre, F. X., Bily, A., \& Chemat, F. (2016). Towards a "dry" biorefinery without solvents or added water using microwaves and ultrasound for total valorization of fruit and vegetable by-products. Green Chemistry, 18(10), 3106-3115. http://dx.doi.org/10.1039/ C5GC02542G.

Li, Y., Fabiano-Tixier, A. N., Tomao, V., Cravotto, G., \& Chemat, F. (2013). Green ultrasound-assisted extraction of carotenoids based on the bio-refinery concept using sunflower oil as an alternative solvent. Ultrasonics Sonochemistry, 20(1), 12-18. http://dx.doi. org/10.1016/j.ultsonch.2012.07.005.

Lingyun, W., Jianhua, W., Xiaodong, Z., Da, T., Yalin, Y., Chenggang, C., Tianhua, F., \& Fan, Z. (2007). Studies on the extracting technical conditions of inulin from Jerusalem artichoke tubers. Journal of Food Engineering, 79(3), 1087-1093. http://dx.doi.org/10.1016/j. jfoodeng.2006.03.028.

López, M. G., \& Urías-Silvas, J. E. (2007). Agave fructans as prebiotics. In N. Shiomi, N. Benkeblia \& S. Onodera (Eds.), Recent advances in fructooligosacharides research (pp. 297-310). Kerala: Research Signpoint.

López, M. G., Mancilla-Margalli, N. A., \& Mendoza-Diaz, G. (2003). Molecular structures of fructans from Agave tequilana Weber var. azul. Journal of Agricultural and Food Chemistry, 51(27), 7835-7840. http://dx.doi.org/10.1021/jf030383v.

Mancilla-Margalli, N. A., \& López, M. (2006). Water-soluble carbohydrates and fructan structure patterns from agave and Dasylirion species. Journal of Agricultural and Food Chemistry, 54(20), 7832-7839. http://dx.doi.org/10.1021/jf060354v. 
Maran, J. P., Mekala, V., \& Manikandan, S. (2013). Modeling and optimization of ultrasound-assisted extraction of polysaccharide from Cucurbita moschata. Carbohydrate Polymers, 92(2), 2018-2026. http://dx.doi.org/10.1016/j.carbpol.2012.11.086.

Mellado-Mojica, E., \& López, M. G. (2012). Fructan metabolism in A. tequilana Weber blue variety along its development cycle in the field. Journal of Agricultural and Food Chemistry, 60(47), 1170411713. http://dx.doi.org/10.1021/jf303332n.

Mellado-Mojica, E., López-Medina, T. L., \& López, M. G. (2009). Developmental variation in Agave tequilana Weber var. azul stem carbohydrates. Dynamic Biochemistry, Process Biotechnology and Molecular Biology, 3, 34-39.

Milani, E., Koocheki, A., \& Golimovahhed, Q. A. (2011). Extraction of inulin from Burdock root (Arctium lappa) using high intensity ultrasound. International Journal of Food Science \& Technology, 46(8), 1699-1704. http://dx.doi.org/10.1111/j.1365-2621.2011.02673.x.

Miller, G. L. (1959). Use of dinitrosalicylic acid reagent for determination of reducing sugar. Analytical Chemistry, 31(3), 420-426. http://dx.doi. org/10.1021/ac60147a030.

Minitab. (2010). Statistical Software 16. State College: Minitab.

Narváez-Flores, M., Sánchez-Madrigal, M. Á., Quintero-Ramos, A., Paredes-Lizárraga, M. A., González-Laredo, R. F., Ruiz-Gutiérrez, M. G., Piñón-Castillo, H. A., \& Meléndez-Pizarro, C. O. (2015). Ultrasound assisted extraction modeling of fructans from agave (Agave tequilana Weber var. Azul) at different temperatures and ultrasound powers. Food and Bioproducts Processing, 96, 232-239. http://dx.doi.org/10.1016/j.fbp.2015.08.007.

Norma Oficial Mexicana - NOM. (2006). NOM-006-SCFI-2005: bebidas alcohólicas-tequila-especificaciones. Estados Unidos Mexicanos: Secretaría de Economía.

Pardo-Rueda, A. J., Quintero-Ramos, A., Genovese, D. B., CamachoDávila, A., Zepeda-Rodríguez, A., Contreras-Esquivel, J. C., \& Bizarro, A. P. (2015). Efficient extraction of fructans from sotol plant (Dasylirion leiophyllum) enhanced by a combination of enzymatic and sonothermal treatments. Food and Bioproducts Processing, 94, 398-404. http://dx.doi.org/10.1016/j.fbp.2014.05.005.

Pinal, L., Cornejo, F., Arellano, M., Herrera, E., Nuñez, L., Arrizon, J., \& Gschaedler, A. (2009). Effect of Agave tequilana age, cultivation field location and yeast strain on tequila fermentation process. Journal of Industrial Microbiology \& Biotechnology, 36(5), 655-661. http://dx.doi.org/10.1007/s10295-009-0534-y.

Pingret, D., Fabiano-Tixier, A. S., \& Chemat, F. (2013). Degradation during application of ultrasound in food processing: A review. Food Control, 31(2), 593-606. http://dx.doi.org/10.1016/j.foodcont.2012.11.039.
Ritsema, T., \& Smeekens, S. (2003). Fructans: beneficial for plants and humans. Current Opinion in Plant Biology, 6(3), 223-230. http:// dx.doi.org/10.1016/S1369-5266(03)00034-7.

Ronkart, S. N., Blecker, C. S., Fourmanoir, H., Fougnies, C., Deroanne, C., Van Herck, J.-C., \& Paquot, M. (2007). Isolation and identification of inulooligosaccharides resulting from inulin hydrolysis. Analytica Chimica Acta, 604(1), 81-87. http://dx.doi.org/10.1016/j.aca.2007.07.073.

Santos, H. M., Lodeiro, C., \& Capelo-Martínez, J. L. (2009). The power of ultrasound. In J. L. Capelo-Martínez (Ed.), Ultrasound in chemistry: analytical applications (pp. 1-6). Weinheim: Wiley-VCH Verlag GmbH \& Co. KGaA.

Waleckx, E., Gschaedler, A., Colonna-Ceccaldi, B., \& Monsan, P. (2008). Hydrolysis of fructans from Agave tequilana Weber var. azul during the cooking step in a traditional tequila elaboration process. Food Chemistry, 108(1), 40-48. http://dx.doi.org/10.1016/j. foodchem.2007.10.028.

Wang, Y., Liu, Y., \& Hu, Y. (2014). Optimization of polysaccharides extraction from Trametes robiniophila and its antioxidant activities. Carbohydrate Polymers, 111, 324-332. http://dx.doi.org/10.1016/j. carbpol.2014.03.083.

Xu, Y., Zhang, L., Bailina, Y., Ge, Z., Ding, T., Ye, X., \& Liu, D. (2014). Effects of ultrasound and/or heating on the extraction of pectin from grapefruit peel. Journal of Food Engineering, 126, 72-81. http:// dx.doi.org/10.1016/j.jfoodeng.2013.11.004.

Zhang, D. Y., Wan, Y., Xu, J. Y., Wu, G. H., Li, L., \& Yao, X. H. (2016). Ultrasound extraction of polysaccharides from mulberry leaves and their effect on enhancing antioxidant activity. Carbohydrate Polymers, 137, 473-479. http://dx.doi.org/10.1016/j.carbpol.2015.11.016.

Zhang, L., Ye, X., Ding, T., Sun, X., Xu, Y., \& Liu, D. (2013). Ultrasound effects on the degradation kinetics, structure and rheological properties of apple pectin. Ultrasonics Sonochemistry, 20(1), 222-231. http:// dx.doi.org/10.1016/j.ultsonch.2012.07.021.

Zhao, Z. Y., Zhang, Q., Li, Y. F., Dong, L. L., \& Liu, S. L. (2015). Optimization of ultrasound extraction of Alisma orientalis polysaccharides by response surface methodology and their antioxidant activities. Carbohydrate Polymers, 119, 101-109. http://dx.doi.org/10.1016/j. carbpol.2014.11.052.

Zhu, Z., He, J., Liu, G., Barba, F. J., Koubaa, M., Ding, L., Bals, O., Grimi, N., \& Vorobiev, E. (2016). Recent insights for the green recovery of inulin from plant food materials using non-conventional extraction technologies: a review. Innovative Food Science \& Emerging Technologies, 33, 1-9. http://dx.doi.org/10.1016/j.ifset.2015.12.023.

Zou, Y., Xie, C., Fan, G., Gu, Z., \& Han, Y. (2010). Optimization of ultrasound-assisted extraction of melanin from Auricularia auricula fruit bodies. Innovative Food Science \& Emerging Technologies, 11(4), 611-615. http://dx.doi.org/10.1016/j.ifset.2010.07.002. 